\title{
The Problem of Athletes Violence in Sports Competitions and Its Prevention
}

\author{
Mirko Tufegdžija and Ernest Šabić \\ Management in sport, Panevropean University of Apeiron, Banja Luka 78 000, Bosnia and Herzegovina
}

\begin{abstract}
In today's modern world, a will to succeed is inextricably linked with the acquisition of profit, while sports competition turns into an aggressive fight for the result and prestige. The athletes in professional sports, where victory is imperative, often treated as just another object and an obstacle to be overcome. Violence in sports performed primarily athletes themselves. In sports games can be applied aggressive tactics, but the use of violence is considered to be beyond the scope of what is considered to be the good behavior of an athlete. Athletes decide on violence sometimes with a clear goal of hurting the opposing player, and sometimes only for intimidation, in order to win. Extreme exercise, accompanied by great hardships and frequent injuries, are not always sufficient to achieve the required and expected results, and more and more athletes turning to the use of prohibited doping substances, thus trying to improve their own capabilities.
\end{abstract}

Key words: Sport violence, aggressiveness of sportsmen, professional sport, sports competition.

\section{Introduction}

In sports, it has become commonplace that hostile and aggressive behavior is called violence, so it is about the violence of viewers, violence in the field (violent procedures during the game, mutual verbal or physical conflict of players), violence of parents and coaches against athletes, violence against sports judges, violence against sports journalists, etc. However, what is particularly disturbing is the so-called silent violence, under conditions where sport becomes a profitable business in the world and becomes a powerful instrument of political manipulation, especially of large economic forces. It should be borne in mind that all subjects of violence at one point can be actors, and in another victim of violence. These roles vary depending on context, situational influences, personality factors, field events, as well as the course of each concrete training or competition process. By observing and analyzing the links between sport and violence today, we can conclude that "sport" and

Corresponding author: Mirko Tufegdžija, Ph.D., professor, research field: management in sport. "violence" are closely related concepts and particularly complex.

Some authors believe that the root of sport is in violence, in ancient rituals or wars as turning points in the life of society [1]. It is enough to note that violence and what will become "sport" from the old times bring into contact. Antique games (Corinthians, Istam, Neme, and Olympics) offered a degree of disaster to some extent. They were indeed an alternative form of warfare, a form of confirmation of the supremacy of the city-state over rivalries. Physical activities such as pancratium (Greek-Roman wrestling) were extremely violent and sometimes resulted in the death of combatants [2]. Doping was also involved, though it was more concerned with religious and folk beliefs than on a variety of products (mostly synthetic and biological) that are in use today. As today, beliefs have played a major role in achieving the effects of various substances that have been consumed, gut or breathed both in individuals and at the collective level. Some athletes ate a certain type of meat that was consistent with their specialty: pork fat for wrestlers who wanted to increase body mass, jaretine to improve jumping skills [3]. 


\section{Sports Violence on Sports Terraces}

Sports violence is primarily done by athletes themselves. Aggressive tactics may be used in sports games, but the use of violence is considered to be outside the scope of what is considered to be the good behavior of an athlete. Sportsmen resort to violence sometimes with a clear goal of hurting the opponent, and sometimes just intimidating, all in the pursuit of victory.

In today's modern world, the will to succeed is inextricably linked to gaining a profit, so sporting competition turns into an aggressive struggle for result and prestige. Sporting sportsmen, in whom imperative victory, often treat others as just an object and an obstacle to overcome.

We can distinguish several models that explain in detail relationship sportsmen and violence, which are: (1) violence of athletes according to their own body and personality; (2) violence against other athletes and sportsmen; (3) violence against athletes perform sport brokers (coaches, judges, officials, media, sponsors) and fans.

Modern sport, and especially professional, was built on the myth of victory. It is not difficult to get in touch with the official game of the Olympic Games "faster, more, stronger" with the famous story about one coach who said that winning is not the most important thing, but the only thing that exists. Individuals deal with sport for various reasons. Dedication of sports, career, money, glory, health, and self-esteem are just some of the motives that athletes do in their endeavor to defeat. The victory as an imperative, a requirement that sportsmen pose and certain structures of power (politicians, owners of sports clubs, sports officials, and media) gain from the defense of national pride, profit or spectacle, make the top sportsmen overcome their own psycho-physical potential. Tough trainings, followed by great resignations and frequent injuries, are not always sufficient to achieve the required and expected results, and more and more sportsmen are turning to using illegal doping resources to try and improve their own opportunities. There are countless cases of doping of drugs with an unfortunate outcome of the athlete (from fines and imprisonment, humiliation, health problems and even death), indicating that this phenomenon is becoming more and more common in the field of sport violence.

Hosta says, "If this is considered good for the team, then it is good for me, as I am part of that team, leading to the sacrifice of fair play that is the structure and the ethos of top sport" [4]. Brutality is particularly reflected in decisive moments of the competition, especially when it comes to winning the first place or surviving in a certain level of competitions. Sportspeople often, at key moments, crowded pressures frustrated with uncontrolled and almost unconscious aggressive outbreaks. Božović states in his research: "It is manifested through verbal and physical violence on the ground, and it also has far-reaching sociological consequences for the audience around the field, as well as young people looking for their protagonists in sports stars" [5].

Leskošek writes: "Sport is an activity that is characterized by a variety of psychological experiences based on the struggle, competition. Competition is thus the basis of every sport" [6]. Matić and Bokan gave the following definition: "Sport is the preparation process for the competition and the competition only" [7]. Kovačević highlights in his work two sides of contemporary sport. "Sport as the most important cultural phenomenon of modern society, the mechanism of personal and social affirmation, which represents body culture, manifestation of the youth style on the one hand, making positive attitudes. On the other hand, it represents the area of high risk, the expression of the impetus of rivalry, the deformed form of the game, the space of violence, mass manipulation, and the release of tension" [8].

Vejnović speaks of violence in sport as violence against the game, and violence over the game as a form of violence against man, since it is one of the fundamental characteristics of man. By this author, 
"the defeated game is due to the absence of brake and protection, where sport promotes more and more militaristic values, and suppresses those humanistic and as such it is not only a kind of industry but also a form of war" [9].

Ratko Božović was involved in the study of "Aggression and Sport Violence" by researching today's sport, stating that the aggressive game has become the virtue of contemporary sport that is publicly affirmed. Violence in sport, destructive and self-destructive behavior is being pursued in order to achieve the best results [5].

Leskošek in his work "Social-Ethical Aspects of Sport" deals with negative, deviant phenomena in sports and measures that should be taken to eliminate them, or at least to diminish them. Leskošek states that "there are manifestations that are reflected in misplacing sport, com-mercialism, club warmth, egoistic, localist and chauvinistic tendencies, unhelpful atmospheres in clubs and clubs, judges and coaches, gaining victory, bribing, purchasing players, glorifying individual athletes and others" [6].

The moral health of sport is constantly exposed to public interest and valorization. The public experiences sport as a sphere of fair play and a center of moral integrity. As a part of the culture of a society, sport depicts, protects and promotes - it promotes the values and ethics that members of that society respect. When ethics is mentioned in today's sport, the most commonly thought are negative aspects of sports such as corruption, fake amateurism, violence, doping, commercialization, etc. Sports morals or ethics in sports represent a specific awareness of behavior in the process of competitions, training process, in relation to the audience-sportsmen and the public-sporting event. For sociology of sport, morality is a standard of social behavior with the aim of accepting norms and rules alongside sportsmen and coaches, judges, audiences and others. Sport that gives the athletes the opportunity to express their qualities can be the scene of human victories, glory, but it can also be a field of degradation, dehumanization, and violence. There are, in the sport, imperatives that do not contribute to the autonomy of the sportsman's personality, the pleasure of exercising, because they have a requirement for compulsion, commands (by coaches), sanctions that can be applied differently, etc. Educational-educational process aimed at adopting sports standards-rules, positive values and knowledge, sports habits with sporting interest and exercise, provide the opportunity to overcome negative phenomena in sports [10].

There are a large number of terms recognized by the contemporary society, which are increasingly linked to sport, building its dark side. Many terms are not delimitated, they are used as synonyms, but the fact is that all of them together form and build a form of violence that is overwritten in modern sport. Assertive behavior in sports implies a strong, decisive, strong game in which players use legal means to reach the goal. As a result, assertiveness is undoubtedly an essential component of sporting success. Aggressiveness in sports is behavior beyond the rules of sports that is intentionally directed at the injury or injury of other participants. According to Ristić, aggressive behavior is categorized into three categories where, besides asctuarial behavior, there is also instrumental and hostile aggression. In sports, if it is basically such a behavior: the desire to achieve some ultimate goal, then it is instrumental or "good aggressiveness" if the desire to cause pain and injury to another person-an unfriendly (hostile) or "bad" aggressiveness [11].

He does not judge, therefore, sport, but what he does or wants to do. It is important that those at various levels involved in sport, from participants to senior officials, have in mind that sports grounds remain a place of fusion, a place of communication between individuals on the opposite sides of culture, politics and religion, and place in which these individuals achieve what little politicians are doing by hand, which is a certain form of humanism [12]. 


\section{Prevention of Violence in Sports Event}

Sport represents a universal tool in creating and achieving values that change societies, develops national cohesion, affirms democracy, realizes fundamental human rights and freedoms, strengthens the economy and fosters the protection of citizens' health, once sport integrates more national interests. Sport, on the one hand, raises the attachment of different groups, nations and cultures, but on the other side of the sport, and in connection with it, various forms of violence and misconduct often occur. Violence at sporting events is not a phenomenon that is characteristic for this time, unfortunately violence is a historical accompanying sport constant and has not been around by most states in the world.

Dragan Koković points out that "transcending violence in sports requires different physical and sports education, a different relationship between man and his body, and especially towards the body of other people" [13].

Possible preventive measures would be: (1) severe disciplinary, criminal and financial penalties for athletes and sports enthusiasts who violate prescribed sports conduct codes; (2) Organized monitoring of the psycho-physical condition of athletes; (3) Additional education of sportsmen (getting to know the risks involved in using doping agents, getting acquainted with healthy eating habits, getting acquainted with the consequences of overcoming, overcoming, and training without expert supervision).

Any attempt to prevent violence in sports grounds must take into account: (1) a comprehensive social context of events; (2) the specificity of the situation in which disorder occurs; (3) type of event (characteristic features and game type); (4) a specific episode that caused the outbreak of turmoil; (5) Epidemiology of disorder (spread and suppression scheme); (6) repetition of events in time and space span.

It should be stressed that there are different strategies for dealing with violence in sports stadiums: (1) systematic overcrowding; (2) amazement and morality;
(3) the strategy that the stadium sees as a sort of anti-school; (4) Club Control, Disciplining, and Domesticization of Players Affected by Violence; (5) a strategy centered on the organization of matches and technical protection measures at stadiums.

\section{Conclusion}

Following the existing definition of sport, it can be concluded that the competition is in its essence, and all the relations that take place in the sports struggle, but also beyond, represent the value of sport. The choice of sports values is made up and built by players, coaches and all club management, fans, field and outdoors. They all make the company and participate in creating a unique image of sports. The sporting image has gone back years and will change because it is conditioned by the evolution of society. It can be stated that the increasing number of terms that arise and build unfortunately the dark side of the sport. Contemporary society recognizes various forms of violence that need to be observed in a multidimensional way because there is no clear boundary between them, they intertwine and condone each other. It should be emphasized that good personal traits, good character and moral behavior are taught through life, are relatively persistent personality traits, and can not be lost at the moment under mass pressure.

\section{References}

[1] Jeu, B. 1975. The Sport, Mortality, Violence, PUL, Lille, call "Ethics and sport in Europe". Paris, 2011.

[2] Jeu, B. 1987. Sport Analysis, Paris: PUF, call. "Body Practices". Paris, 1992.

[3] De Mondenard, J. P. 2000. Dopage, The Imposture of the Performances. Paris: Chiron, 7.

[4] Hosta, M. 2007. Sports Ethics-Manifesto for the 21st Century. Ljubljana: Faculty of Sport.

[5] Božovoć, R. 2007. "Aggression and the Race in Sports." Sociological Class 1 (2): 100-12.

[6] Leskošek, J. 1981. "Social-Ethical Aspects of Sportage." Physical Culture 35 (1): 12-7.

[7] Matić, M., and Bokan, B. 2005. General Theory of Physical Culture. Belgrade: Faculty of Sport and Physical Education. 
[8] Kovačević, B. 2011. "Society of Violence and Sports." In Proceedings at the Violence and Sports, Banja Luka, 38-46.

[9] Vejnović, D. 2011. "Violence in Sports as a Segment of the Violence in Society with the Focus on the Fan Club." In Proceedings at the Violence and Sports, Banja Luka, 12-27.

[10] Kozarčanin, A. 2008. "Ethics in Sports." Sport Science 1:
54-6.

[11] Ristić, L. 2011. "Violence in Sports and the Perpetration of Aggressive Impulses." In Proceedings at the Violence and Sports, Banja Luka, 12-27.

[12] Bodin, D., Robene, L., Heas, S. 2007. Sport and Violence in Europe. Zagreb: Book of Commerce.

[13] Koković, D. 2000. Sociology of Sports. Belgrade: Sports Academy. 